\title{
The Creative Studio Practice of Contemporary Dance Music Sampling Composers
}

\author{
$\because$ FeAture Article $\longrightarrow$ \\ JUSTIN MOREY \\ Leeds Metropolitan University (UK) \\ PHILLIP MCINTYRE \\ University of Newcastle (Australia)
}

\begin{abstract}
This paper seeks to investigate some of the considerations that inform and help to determine the creative studio practice of contemporary sampling composers. Collaborative writing and production, specifically the co-opted collaboration implicit in using samples, will be assessed to consider those aspects of the production process which the participants consider to be authorial. These considerations include acts of listening, selecting and editing. In examining these matters, this paper places emphasis on how sampling composers actively constrain their options in order to promote a creative relationship with their musical material. Techniques such as, firstly, traditional sample manipulation, secondly, the use of a sample as an initial building block for a composition from which the sample is then removed and, finally, live performance in the studio which is subsequently cut up and treated as a sample, will be discussed. Case studies, in the form of semi-structured interviews with sampling composers, will be drawn upon to assess approaches to and views about these forms of studio composition.
\end{abstract}

KEYWORDS: sampling, technology, creative practice, legal framework, social context

JUSTIN MOREY has a background in sound engineering and music production, running his own recording studio in London from 1995-2003. He has been teaching in higher education since 2001. His main research interest is in sampling as a creative practice within British dance music. His research has been published in the IASPM-Norden Music, Law and Business Anthology (IIPC), the IASPM Journal 2012 Digital Nation Special Edition, and the Journal on the Art of Record Production (JARP), two of which are co-authored with Phillip McIntyre.

Phillip MCInTyre has been involved in the music industry for the past thirty years where he has been a songwriter, instrumentalist, musical director and manager. He has worked as a music journalist and produced and engineered audio and video recordings. He currently teaches sound production at the University of Newcastle Australia. His latest book is entitled Creativity and Cultural Production: Issues for Media Practice. More detail on Phillip McIntyre can be found at: $<$ http://www.texasradio.com.au/pages/mcintyre p.html\#top>

Dancecult: Journal of Electronic Dance Music Culture 6(1): 41-60

ISSN 1947-5403 @2014 Dancecult http://dj.dancecult.net

DOI 10.12801/1947-5403.2014.06.01.03

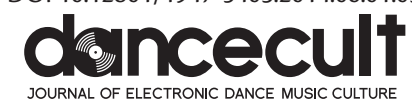




\section{Background to the Study and Methodological Approach}

Previous work by the authors has explored the ways in which advances in studio technology have afforded those involved in collaborative popular music composition a range of creative approaches which have, in turn, led to non-traditional decisions when considering the kinds of contributions to the production process that can and are considered to be authorial (McIntyre and Morey 2010). A more recent study (McIntyre and Morey 2011) sought to identify the creative practice of sampling composers in terms of the influence of a complex system of technological, social, cultural, economic, legal, historical and geographical factors, which derived its theoretical perspective from McIntyre's work on creativity and cultural production (McIntyre 2007, 2008, 2009a, 2009b, 2010, 2012). This work presents evidence to support the idea that creative action occurs as the result of a dynamic system in action. In building on this work this article aims to explore some of the specific studio practices employed by composers who have worked, or continue to work, with samples, and the extent to which these approaches to writing and creating music may be distinct from those of composers and studio practitioners for whom the use of phonographic samples does not represent a significant part of their creative methodology.

A case study methodological approach (Yin 1989) was employed in our research. Interviewing was the single method adopted following the realisation that while triangulation using multiple methods is common to many positivist approaches, it may be "rooted in a scientifically naive notion that multiple methods can reveal a single, 'true' reality beyond frameworks of theory and interpretation" (Jensen and Jankowski 1991: 63). For us the goal has not been to come up with a global statistical generalisation (Yin 1989: 21) but instead, following the dictums of qualitative research, an attempt to uncover the meaningful activity of sampling composers. We have used a convenience sample (Lull 1990: 19) for this research project, and for brief biographical details of those involved with the study please refer to page 60.

It should be acknowledged here that the case study sample comprises UK sampling composers who have worked across a range of dance music styles that incorporate samples, including house, techno, early hardcore, breakbeat, big beat, dubstep, hip hop, trip hop and ambient house. As such, it is not within the scope of the study to draw any conclusions about dance music practice globally, or indeed about practice in genres of dance music outside of those created by our case study sample. Given the variety of music that our interviewees have worked on however, it may be reasonable to assume that some of the approaches to composition and production discussed hereafter may be employed by dance music composers working in other genres and other countries. It is also worth noting that the term "sampling composers" will be used throughout the article to refer to the interviewees and any third parties engaged in similar activities of cultural production, because this is more convenient than the often interchangeable use of terms such as "artist", "producer", "DJ" and "programmer", and because the prime concern here is with sampling as an authorial and compositional activity. We would also argue that the term "composer" has had a tendency 
to be reserved in musicological literature for individuals producing either orchestral music, or what might be classified as art music, and that the term deserves to be used more widely in reference to those working within what may be broadly described as popular music.

\section{CO-OPTED AUthoRSHIP}

The use of intertextual devices as a necessary form of meaning-making has not only been recognised as a form of reference for consumers of texts but it is increasingly seen as a basic mode of creative activity by producers of communicative texts. As Roland Barthes argued, all texts occur in "a multi-dimensional space in which a variety of writings, none of them original, blend and clash. The text is a tissue of quotations drawn from the innumerable centres of culture" (1977: 146). While these ideas largely refer to a conceptual practice related to consumption, intertextuality is increasingly recognised as a fundamental technique of creative production in as much as all things come into being from a set of antecedent conditions (Aristotle 1960: 142). For sampling composers, these modes of intertextual action, that draw on pre-existing works, operate as an extended form of co-creation rather than existing as merely a conceptual activity. By incorporating third party samples in their work, literally derived from other texts, sampling composers effectively co-opt the writers (though not necessarily the performers) of the sampled work as co-authors once the sample clearance process has been agreed. A recent example of the potentially circuitous nature of this is the Plan B song "Ill Manors", which sampled the string arrangement from the German pop musician Peter Fox's 2008 song "Alles Neu”. These string parts were taken (but rearranged and rerecorded rather than sampled) from the fourth movement of Shostakovich's $7^{\text {th }}$ symphony, leading to the following writing credits for "Ill Manors":

Ben Drew [Plan B], A Shuckburgh [his co-composer], Vincent Von Schlippenbach, David Conen, Pierre Baigorry [the three writers of "Alles Neu"], Dmitri Shostakovich [who also receives a co-composer credit on "Alles Neu"]

Using and clearing samples will clearly have an economic impact on those composers who use them, and there is evidence both that costs of clearance have risen significantly in the last ten years, and that sampling composers have modified their practice as a result (see Morey 2012a, 2012b for a full discussion of this). Despite the expense involved, a number of our interviewees felt that there was an ethical obligation for these co-opted writers to be rewarded in cases where the use of the sample was substantial and obvious:

I basically think, my honest opinion is that if you use a sample and you can hear it and it's totally obvious, and everyone knows, or even the trainspotters know, you have to pay your dues for that because it's enhancing your music. ${ }^{1}$

I suppose if you're using something as a sound source, if you're taking a held chord or a note or something like that, then replaying that, I think that should be allowable really. I think if you're taking a whole four bar loop or something, then that's a different case. ${ }^{2}$ 
I think certainly if someone sampled four bars of my music I'd expect something for it. ${ }^{3}$

I've declared samples, I've not declared samples. I think it depends on how much you use. ${ }^{4}$

I think that in a perfect world, if everybody was reasonable, if you're using something that's basically musically recognizable or sounds good because of somebody else's playing or somebody else's writing, then yeah, you should clear that. And if you thought you were going to get treated fairly, I think that people would be much more like 'yeah, that's just what you do'-do you know what I mean? A bit like paying a session musician. When it's just like a noise that's twisted up beyond all recognition, it doesn't really matter about the original, whatever it was, because it's changed, it's something else. ${ }^{5}$

While there was a consensus that sampling a significant part from another record should be reflected by a clearance fee and/or a co-write, one mismatch that can be identified is of that between the contribution made by songwriters to a recording, and the elements of a record that the sampling composer may be interested in using. The writers of a song were historically considered to be (and still are considered to be in many cases) the creator(s) of the melody line, underlying chord structure and lyrics. This is largely a matter of convention, but this situation, as has been noted elsewhere (McIntyre 2001: 103, 106-9 and Wicke 1990: 15-16), may have resulted from changes in the way music has been interacted with. Once musical interaction moved from the music hall and the family piano toward the recorded arena, the principal musical object interacted with also changed. For those who predominantly interacted with sheet music the obvious points of reference were with what could be seen on the sheet, that is, the lyric, the melody and what was often a simple harmonic accompaniment. Once gramophones and records became the primary mode of musical interaction, what was predominantly engaged with changed, leading to a fuller interaction with the performance characteristics of a piece, as well as a greater concentration on arrangement and production values of what was now mainly a recorded sound work. As a result of these changing relationships some have claimed, as Hennion does, that "the song is nothing before the arrangement"-arguing that creation "occurs at the moment of orchestration, recording, and sound mixing" (Hennion quoted in Fitzgerald 1996: 20-21). In this regard, sampling composers take these ideas one step further, often taking sections of the underlying groove of a song or moments when the song drops to a single instrument, such as a bass run or a drum break and using these fundamental elements as the basis for composition. In Zak's framework for compartmentalising studio production, these are elements that belong largely to the third "compositional layer" or "track", with the other two layers being the "song" and "arrangement" (2001: 24). They are often sections of performance by the studio musicians that are not part of what might be notated as the "song", and for which those musicians receive no income as a result of being sampled (income from sample clearance goes to the songwriters and rights owners-the record company and publisher-but there are no royalties for the performers on the sample, as there would be 
on the original record, unless they also happen to be the writers or co-writers). For example, Clyde Stubblefield of the JBs and Gregory C. Coleman of The Winstons, performers of the "Funky Drummer" and "Amen" breaks respectively, two of the most widely-used samples, are not credited as co-authors of the songs containing their performances. As such, it can be argued that the co-authors in a record using samples often have little or no authorial input on the sections of music being used. The overall sound, texture or rhythmic feel of a sample were repeatedly identified by our interviewees as the main characteristics that lead them to use it:

Sometimes we might sample a drum loop that's amazing, you know it's got a fantastic sound. For us it's the atmosphere that it gives [to] something... so more for the sound and the feel that a sample would give you rather than the playing. I don't think we ever sampled anything specifically for the melody. ${ }^{6}$

So we sort of chanced upon all this stuff that we weren't really aware of because it wasn't part of our generation really. It was probably the sort of music that would have been frowned upon by the post-punk generation, stuff like Steely Dan and America. We really liked the kind of woody warmth to that stuff, which was all obviously produced in lovely studios, and the sound you were getting off the vinyl ... and just taking little bits of that, you know, tiny little loops of a little bass run or bongo loop or something like that. And hearing that in the context of the cleanliness of the analogue synths and drum machines and stuff like that, we just enjoyed that whole kind of warmth really, and just the way it added this kind of organic dirt. ${ }^{7}$

You know certain things prick up my ears. The sonics, the groove, although nowadays you can change the groove, that's the great thing about it, but it is essentially the sonics. ${ }^{8}$

It was so basic at first, and my attitude to it was so basic; that you just heard something that you liked and took it, and you didn't really examine why you liked it that much. It was only much later when, like what I was saying to you, about realizing the shortcomings of most musicians that I realized that, being a non-musician myself, what was really special about those old records that you were taking bits from. Those players were fucking properly good and the circumstances that they recorded in were atmospherically different than the way modern records are recorded, and that's part of the whole thing. ${ }^{9}$

A lot of the time, it is the sound, not just an addition. It's a rather dull and predictable answer but, depending on your sample source, you can add layers of texture and atmosphere that may be impossible to achieve elsewhere. Of course, there are legions of competent producers creating their own atmospheres with pure electronics that they have sound designed. I'm in complete admiration of that too but I'm also aware that there's a certain snobbery about that, which I could care less for. ${ }^{10}$ 
Bob Bhamra's comment confirms Warner's view that "the grainy, distorted nature of many samples also provide a useful foil to the 'sanitized' quality of the sounds produced by many modern synthezisers, and as a result give a greater range and depth of sound palette" (2003: 30). Richard Barrett's view, meanwhile, appears to support Rodgers' argument that sampling composers prioritise the timbre or "grain" of a sample because "it reveals the tactility and pleasurability of the recording process, and, in the case of much groove-based electronic music, it often reflects a producer's attempt to create a texturally nuanced sound that will elicit physical response from a dancefloor" (2003: 318). In this regard the work of Roland Barthes highlights this important proposition. Barthes (1990) describes, in line with Julia Kristeva, what is called the pheno-song and the geno-song. For these two the pheno-song covers all the formal phenomena which are in the service of communication such as the structure of the language being sung and the rules of the genre being used, all of which take their "bearing directly on the ideological alibis of a period" (Barthes 1990: 295). The genosong on the other hand, and the one that concerns us more directly here, is associated with the "diction" of a piece and is concerned with "the voluptuousness of its sound signifiers" (Barthes 1990: 295). This is what Roland Barthes calls the "grain" in music which elicits a response leading to a form of pleasure he labels jouissance, an ecstatic and physical pleasure that goes beyond the formal distinctions normally relied on to analyse music. Furthermore, as a result of an over-concentration on the semiotic interpretation of music's lyric content there has been insufficient attention paid to the sounds themselves, to the intramusical structures of what Middleton calls the "primary level of signification" (1993: 177).

Chang has also noted similar distinctions between the prioritisation of sound over melodic content:

The conception of creativity as the construction of diverse, unexpected relationships is a reminder of the distinct conceptions of sound-as-object in instrument-based and sample-based music. Sample-based music uses sounds instrumentally, rather than using instruments to make sounds. In sampling, sound marks the beginning of the creative process, and is accordingly treated as raw material. Instrument-based music treats sound as an ontological object, in which sound is considered the end of the process (2009: 145).

This emphasis on timbre over melody further enforces the idea that the co-opted participants in sample based music will often be the musicians that played on the sampled track, and that moments of performance that are sonically pleasing are often of more interest to sampling composers than identifiable riffs or melodies. These composers could be said to be assembling a group of unknowing and uncredited session musicians who have never met, and finding a way to make these different moments of performance work together. Andy Carthy, for one, views his sampling practice in this way:

I think when you're working in isolation using bits of other people's music, or even if you're adding bits of your own or working with other musicians, I always try and give each element its own personality, even if it's imagining it as a little cartoon figure, like 
a member of the Muppets' band or something, and then it's almost like you've created this little band and you're trying to get them to talk to each other and have fun playing together. And once they're all happy, that's when you know that the track's working. It's almost personalising something that's quite mechanical. Every element you pick is there for a reason and has its own little personality anyway, so it's getting all these different musicians who've never met each other to talk to each other and have a good time, probably without anyone ever realising it. ${ }^{11}$

Simon Reynolds likens an audio recording and a sample taken from it to a "residual ghost", that is "unaware of change in its surroundings and continues to play the same scene repeatedly" (Reynolds 2012: 313). Reynolds has also noted that much of the discourse surrounding sampling has been written largely in its defence, and offers the concern that the time-based nature of sampling and repeating musical performance presents issues that do not arise from other forms of appropriation art, such as collage:

Recording is pretty freaky, then, if you think about it. But sampling doubles its inherent supernaturalism. Woven out of looped moments that are like portals to farflung times and places, the sample collage creates a musical event that never happened; a mixture or time-travel and séance. Sampling involves using recordings to make new recordings; it's the musical art of ghost co-ordination and ghost arrangement. It's often compared with collage. But the added dimension of time that music inhabits makes sample-based music profoundly different from photomontage. With recorded music, however much it's doctored and enhanced through studio techniques (multitracking, overdubs et al.), what you hear is a sequence of human actions happening in real time. (I'm talking about played music here, of course, but that is overwhelmingly what gets sampled, rather than music that has programmed rhythms or is made with digital technology.) To take a segment of living time-which is what a sample is-and chain it into a loop isn't just appropriation, it's expropriation. In a certain sense-neither literally true nor utterly metaphorical—sampling is enslavement; involuntary labour that's been alienated from its original environment and put into service in a completely other context, creating profit and prestige for another (Reynolds 2012: 313-14).

Although approaching sampling from very different philosophical viewpoints, it is interesting to note a certain convergence in describing what happens, between Carthy's metaphor of working with cartoon figures, and Reynolds' "ghost co-ordination and ghost arrangement" (2012: 313). While the idea of samples, and indeed recordings in general, as audio ghosts is persuasive, Reynolds' criticisms of sampling ignore the contribution of the sampling composer, and assume that listeners will hear a sample-based composition differently to "a sequence of human actions happening in real time" (2012:314). Reynolds himself has acknowledged surprise of the speed at which listeners became normalised to sample-based music and "how it just became an everyday part of our listening lives to enjoy-and to accept as music" (2012: 311), while Simon Frith has argued that the distinction between a played performance and a constructed performance may be slight as 
far as the listener is concerned:

I listen to records in the full knowledge that what I hear is something that never existed, that never could exist, as a 'performance', something happening in a single time and space; nevertheless, it is now happening in a single time and space: it is thus a performance and I hear it as one (Frith 1996: 211).

While there may be unresolved issues surrounding both the ethics of co-opting authors and players to contribute to a sampling composition, and the extent to which copyright law enforces a mechanism for some of these contributions to be rewarded and not others, our interviewees have demonstrated a clear desire to continue to assemble compositions by these means, which prompts some discussion of how far listening may be the fundamental compositional strength of these composers.

\section{LISTENING AS AUTHORSHIP}

Csikszentmihalyi has argued that within any given domain, creativity can be seen as the result of agents with the requisite immersion and skill producing something of sufficient novelty that it becomes recognised and validated by the field (Csikszentmihalyi 1988: 329). In terms of sampling practice, some, such as Schloss (2004: 66), have argued that the complexity of the transformation or manipulation of a sample can be seen to be a measure of validation by the field that the sampling composer in question has produced something of creative note. While our interviewees certainly acknowledged sampling composers who undertook considerable manipulation of samples (known as "chopping" and "flipping" in hip-hop production), it was interesting that they generally placed no greater values on these technical skills than they did on the ability to identify a sample that would work within a given context. As such, the ability to listen and select was considered as compositionally significant as any production or technique-based skills:

Sometimes I think as a programmer or producer you're thinking 'I've got to do something to this to justify my involvement' but sometimes actually all you need to do is [say] 'I've selected that two seconds of music, and there's absolutely nothing I can do to improve it. I've chosen it, there you go.' ${ }^{12}$

I think the skill, really, is in recognising a good sample. I find a lot of the stuff I've got is very odd little bits of tracks or ends of records, things like that. There's barely anything there really, but it's kind of knowing when you've heard something that's going to work really. I think that's the thing that comes from doing it for a long time. ${ }^{13}$

I think sampling is just one of those things that, you know ... you just hear something and it has to be that that has to be used..$^{14}$

Richard Barratt prioritises listening over other studio or compositional skills, and explains why he has made a conscious decision to avoid learning sample manipulation: 
To tell you the truth, I wouldn't even go anywhere near the computer-I'd just tell the engineer what sounds good. I really don't give a fuck about any of it. I'm not interested in getting involved with pressing keys on a keyboard or pressing keys on a computer, because I think as soon as you start doing it, you can't hear what you're doing any more. It becomes like an exercise in twatting about, rather than being able to hear the music. Do you know what I mean? I'd rather sit back from it. I think it's a musician's disease really. As soon as you start playing things, and if you play it yourself, you start listening to it in a different way than if it was someone else who's playing it, and then it's very easy to lose your perspective very, very quickly. ${ }^{15}$

Andy Carthy explains in more detail why he thinks that having an ear for a good sample is as important a creative act as sample manipulation, or creating a work from a number of small, less identifiable fragments:

You know, some of my favourite sample tunes are not doing too much to the sample. That's a thing as well, because people think, "well, you've not added anything to it". You listen to something like "The 900 Number", and that's a Marva Whitney tune on 33, it's a two bar loop and Mark's [DJ Mark, The $45 \mathrm{King}$ ] production technique is just adding drum machine hits at relatively low volume behind-just very subtly toughening up the original drums on the record but without obviously being beefed up too much .... I'd hate it if he started adding loads of extra elements to his music, but his ear for choosing a good sample that you will want to listen to over and over again for five minutes is undeniable, you know what I mean? So it's sometimes just that pure repetition of something which is so sublime that you don't want anything to change about it over and over again - that's one of the elements that I really like about sampling. Or you listen to, say, DJ Premier or something like that. A lot of his best tunes, stuff like the Crooklyn Dodgers tune with the really heavy brass loop and the little bell dinging at the end of it. 4 bar loop-probably he's not even chopped that up. Kick and a snare-that's it! Couple of cuts on the chorus, but absolutely killer, you know what I mean? .... The same thing can apply to art. You know, is Seurat with his kind of pointillist intricacy more viable than a Mark Rothko? I don't know. Is it? Something isn't better simply because it's more complicated or been interfered with more, because sometimes you want to show the beauty of what you're actually using. ${ }^{16}$

Carthy's views recall Warner's comment that the sampling composer "need not be a physical virtuoso, only a virtuoso of the imagination with an expertise in the manipulation and organization of sound", whose "musical imagination is likely to have developed largely through listening to recordings" (2003: 96-7). Warner also references Nattiez's idea of an esthesic dimension in the construction of musical meaning; rather than some traditional ideas of communication theory where the meaning of a text is "a producer's transmission of some message that can be subsequently decoded by a 'receiver" (1990: 9), reception is, in line with Roland Barthes' (1977) ideas mentioned above, "a complex process that reconstructs a 'message" (1990: 17), where listeners "construct meaning in the course of 
an active perceptual process" (1990: 12). Warner argues that this view of reception is particularly useful when considering music created with samples, because the life experience of the listener may have significant consequences to their apprehension:

When a listener identifies the source of a sample, the extra-musical connotations (be they physical, cultural or phonographical) inform the purely musical response. These non-musical associations become part of the interpretative process; the listener's understanding of the piece is dependent on whether identification takes place, and a culturally informed response is quite different to a musically informed response. Physical, cultural or phonographical signs replace or override musical signs and, as a consequence, a different kind of communication takes place (Warner 2003: 97).

It can be argued that our sampling composers interviewed here are hyper-listeners-they have a deep knowledge, not only of sample-based music, but of the often obscure origins of many of the samples used by their forebears and peers (both Barratt and Reeves use the term "trainspotters" to describe what some might see as the geeky obsessiveness of the serious vinyl collecting DJ).

For the sampling composers in this study, one of the key skills appears to be identifying a very short section of groove from a record, and having a feel for how that groove, and smaller sections derived from it, will work when repeated. For example, Martin Reeves' (Krafty Kuts) track "The Funk Is" (2001) features two bars of Fender Rhodes electric piano and guitar, although it is unclear without knowledge of the original sampled source if this two bar phrase is sampled from one place in the original record, or itself constructed from multiple locations, or indeed multiple records. The stereo location of the main Fender Rhodes riff (centre) and the two guitar parts (strummed chord fairly hard right and staccato palm muted guitar centre left) suggests that all three of these parts could be from different sources, while the three note electric piano phrase that features in the final two beats of the two bar phrase is sufficiently different both sonically and tonally from the other material to suggest that it is either sampled from another source, or has been played in, or programmed from a sampled keyboard instrument. The full loop can be heard for the first time at 1.06. Elsewhere, variations derived from this loop have been created to provide changes in the groove and dynamic of the piece. At 37 seconds, in the introduction, a four bar loop is created from repeating beats one and two of bar two of the original loop 14 times, followed by the last two beats of resolution from the original loop, with the addition of a single electric piano chord on the final off beat of bar two, and a stuttering of the main Fender Rhodes sample in bar three. At 1.36, a different variation occurs where the first bar of the two bar loop is repeated three and a half times, followed by the final two beats as resolution, while at 1.50 , the original loop is returned to but with an additional electric piano hit on the final off-beat of bar one. On each occasion, the drums and bassline are also altered to fit with these changes while retaining the sense of forward motion. It could be argued that none of these variations would be likely to appear as a played repetitive groove on, say, the kind of funk and jazz funk records that Reeves may have used to obtain his samples, because 
musicians will naturally introduce slight variations in a repetitive groove and because the idea of repeating a single beat from a main riff to form a different riff would be uncommon, and by the nature of live musicianship, still contain minor variations, rather than being exact copies.

Reeves has produced something distinctive, which manages to avoid sounding mechanical because of the careful choice of elements of groove from which it has been composed. Given significant technical skill as a turntablist, and sufficient record decks and copies of the record, it would be technically possible (although very challenging) to recreate much of the variation composed here by Reeves, which suggests that his compositional approach and resulting sound derives from the habitus of both DJ and studio-based composer. As Richard Burgess asserts:

We're not talking about the kind of instinct that you're born with. This is the instinct that develops from being around music, musicians and studios your whole life. This, I think, is the reason that DJs with no musical or technical ability can still become excellent producers. They have listened to many, many records, logged the way people responded to the music and subconsciously programmed their instinct to be able to reproduce those excitement factors in their own records (1997: 177).

As Reeves indicated, "you just hear something and it has to be that that has to be used". ${ }^{17}$ This process of gaining an instinct for what will work can be associated with the acquisition of a sampling composer's habitus, which has been described as:

A 'feel for the game', a 'practical sense' (sens practique) that inclines agents to act and react in specific situations in a manner that is not always calculated and that is not simply a question of conscious obedience to rules. Rather it is a set of dispositions which generates practices and perceptions. The habitus is the result of a long process of inculcation, beginning in early childhood, which becomes a 'second sense' or a second nature (Johnson in Bourdieu 1993: 5).

The development of a producer's or composer's habitus is centred in many cases on the ability to switch from listener to composer and back again, as suggested above, to the extent that these two roles, focused on either listening as production or listening as consumption, will, at times, become indistinguishable. These ideas of the complexity of listening fit well with the proposition that the processes of production and consumption in communication, which have often been

$[\mathrm{t}]$ reated as isolated parts of a uni-linear process, are not seen here as separate entities. It is argued that they can only be isolated from the system [of communication] for purposes of analysis as they constitute integrated aspects of the system itself and are themselves constituted by it. It is this system that brings meaning into being. This is how messages are created (McIntyre 2012: 8). 


\section{The Constraints of Samples as Compositional Tools}

In creating a musical work, a sampling composer's "agency, the ability to make and effect decisions, is dependent on the structures, principally the domain and field, they encounter and surround themselves with. As such their freedom to act is relative to the domain and field they work in" (McIntyre 2009a: 7). The existence of the limits set by the domain and field are not only constraining factors but they also enable creative action. Janet Wolff argues the existence of these so-called limits actually enables creative activity. She suggests that "all action, including creative or innovative action, arises in the complex conjunction of numerous determinants and conditions" (Wolff 1981: 9).

Further to this, Morey (2012a, 2012b) has argued that sampling composers value the restrictions placed on their compositional process, whether these be the timbral and timing issues inherent in incorporating a completed recording (as opposed to individual parts) into a new record, or the restrictions placed upon them by copyright management in terms of quantitative or qualitative usage of samples. Three approaches to using samples that appear to value these constraints have appeared with sufficient regularity in our interviews for them to be noteworthy.

\section{A) Samples Chopped "By Hand"}

Since the introduction of Propellerhead Recycle software in 1994, it has been relatively straightforward for someone familiar with music production software to take a loop from a recording and, provided that you have found a start and end point on a sampler reasonably accurately (so that it loops smoothly), use software to detect the main transients (or hits) and quantise the loop, either through the software assigning a different MIDI note value to each hit and quantising these notes in a MIDI editor or DAW, or, more recently, through a combination of transient detection and time stretching, such as Logic's Flex Mode. Anecdotal evidence suggests that the use of Recycle was relatively standard in certain genres of UK dance music, especially drum \& bass, where the combination of using sampled drums and the need for a tightly quantised rhythm track that can be edited easily via MIDI, made it a very useful tool in speeding up workflow. Out of our group of sampling composers, however, only Aston Harvey said that he used it regularly, and only began doing so in 2001, seven years after its release, while Paul Hammond has started to use Ableton for time correction, but only very recently. The other interviewees preferred to edit "by hand", i.e. cutting and trimming as many individual slices of the loop as are needed in the sampler or DAW. Andy Carthy explains why he believes this works for him:

I like chopping ... I like using my ears to do that. I'm sure Recycle can be used well and it can save you a lot of time, but I also think any time saving technique also cuts out a lot of the human element which actually makes it appealing. You know, I can chop stuff up as much as is needed, and I really like chopping stuff up in the MPC or chopping stuff up when I'm using a sampler, because I can be playing the tune 
and messing around with the start points, or tuning things up and down. If I record something into Logic, a beat and a loop, I'll just manually chop it up and move it around to get them to fit together. Or you might get a beat tight and then change the tempo because I think the human instinct is to get it as in time as possible. So you can get it really really tight, and then roll the tempo up or down by a couple of BPM, just to suddenly give it quite an odd swing. ${ }^{18}$

Carthy's comments suggest a belief that the affordances of time correction software can push sampling composers into putting everything perfectly in time, and he has taken steps to avoid this in his own practice. However, the fact that most of the producers here prefer not to use time correction software may be more indicative of the point at which they began their careers in music, generally the late 1980s to early 1990s, than of a general avoidance of such tools by sampling composers in general. It also helps to verify Bennett's view of "risk aversion" among both professional studio producers and sampling composers such as Norman Cook (2010: 174-9), suggesting that many professionals are cautious about how new hardware and software may lead to a change in their sound, either because of inherent sonic characteristics, or because of disruption to their established workflow.

\section{B) Start With a Sample, then Discard It}

A practice that emerged as being common to a number of composers was to begin with a sample, as a source of inspiration, build up a composition around it, and then remove the sample altogether. One explanation for this practice is Honer's comment that "sometimes it's better just to start with something than stare at a blank screen"19, but it can also be argued that this method allows the sampling composer to be inspired by the sound and groove of a sample, without the incumbent costs of sample clearance and loss of publishing income to co-opted co-writers.

You can find a part of an old '60s record that you really like and then use a loop of that as a start point and add to it, and add to it, and recreate it, but not recreate it exactly musically, but just use it as a source of inspiration, or for the feel and the rhythm, and then get rid of the sample. So hopefully you've changed it musically but maybe you've kept the tempo and the actual feel of the piece as well. ${ }^{20}$

What we tend to do is to use a sample, like a two or four bar loop as the basis, as the starting point of a track, and then kind of write a track up around it, and then lose the original sample. It's almost like you build up a sculpture around a kind of initial object and then take that initial thing away .... They immediately create a vibe, the subtlety of the way ... I've always generally sampled music that is played by real musicians, rather than sampling electronic stuff, which means that there's that kind of natural swing and ebb to the sample, and then to work around that is the enjoyable aspect really. ${ }^{21}$ 
This process does not entirely fit with any of the collaborative songwriting models proposed by Bennett (2011), although arguably it could be seen as a form of "jamming", except that some of the musicians are not present in the room, nor are they able to modify their performances in response to those who are present. In terms of a songwriting method however, this use of an initial sample that is then discarded very much fulfils the role of "stimulus material" in what Bennett describes as the "six (non-linear and interacting) processes [that] are at play in a co-writing environment-stimulus, approval, adaptation, negotiation, veto and consensus" (2011). Where its use may differ from more traditional songwriting methods is in the sampling composer's view of groove and feel being valued over melody. In addition, while copyright management has restricted their ability to use the sound of a sample, this practice allows them to preserve some of the joy of sampling in their compositions.

\section{C) TREat your own ReCORdings as SAMPLES}

It may not come as a surprise that sampling composers will treat their own musical performances as samples because, arguably, any piece of music that is recorded in a DAW, unless done so in one take with no overdubbing, is constructed from a collection of samples of varying length. As Eliot Bates has argued, "in contemporary computer-based audio recording, every moment of recorded sound is essentially a 'sample.' Thus, rock 'n' roll, country, blues, and classical - genres not traditionally associated with sampling — are now sample-based musics" (Bates 2004: 283 quoted in Harkins 2010: 3). Where the practice, as discussed by our sampling composers, may differ from, say, current pop production methods, is that it appears to arise from a desire to include elements of performance that are not exactly in time or at concert pitch, as would frequently be the case when sampling from vinyl, rather than as a way of eradicating what may be more commonly considered mistakes.

So you know, more and more recently I've just been recording kind of myself attempting to play drums, that kind of thing, almost making a little groove, and then sampling that and kind of and going "right, well I've done that really quickly, I've sampled that, I'm going to record that to two track and use it as a starting point for something else", and not allow myself to go back and mess around with all the individual elements. In the same way as having a sample, you're imposing those restrictions upon yourself, and quite often it's the pushing up against those restrictions and dealing with music that is already completed and using that as the starting point for something else-it's those restrictions which I think really test and encourage your creativity. ${ }^{22}$

We've been using guitar quite a lot, doing a lot of very abstract sort of guitar stuff. We've got millions of guitar pedals that we feed the track back through and all that kind of stuff, a lot of re-sampling things. And we've been playing a lot of the keyboards in live, doing a lot of dubbing of stuff that we then just record as audio and then start chopping that up, and using Ableton to do that really. So we're applying the whole 
kind of sample ethic to it again really, but it happens that the stuff we're making is of our own making rather than being taken off records really, so we're still treating stuff as samples .... I think there are so many options, really, in the software, that you've got to limit yourself. ${ }^{23}$

This compositional approach suggests that sampling composers want to maintain a connection with the techniques that they employ when working with samples, and also indicates an additive approach to composing a rhythm track that is the starting point for the composition. It would be reasonable to assume this compositional method would be more common in studio-based music created by individuals or duos (as is the case with the interviewees in this study for the bulk of their output) than with full bands, but that is not to say it is unique to sampling composers. For example, David Byrne's description of the songwriting process of Talking Heads' Remain in Light identifies a similar approach, which he terms "modular music":

We gave ourselves two weeks to build this instrumental scaffolding ... the vocals would have to come later.... We worked rapidly. One or two people would lay down a track, usually some kind of repetitive groove that would last about four minutes, the presumed length of a song. Maybe it would be a guitar riff and a drum part, or maybe a sequenced arpeggio pattern and an intermittent guitar squeal. Others would then respond to what had been put down, adding their own repetitive parts, filling in the gaps and spaces, for the whole length of the 'song.' As we'd listen to one part being recorded, we'd all be scheming about what we could add - it was a kind of game. This manner of recording had the added advantage that we weren't trying to replicate the sound of the live band. We hadn't gotten attached to the way these songs and their instruments and arrangements sounded in performance, so in some way the conflicts we had confronted when we'd first entered a recording studio years previously were bypassed .... After the tracks began to fill up, or when the sound of them playing simultaneously was sufficiently dense, it was time to make sections. While the groove usually remained constant, different combinations of instruments would be switched on and off simultaneously at different given times. One group of instruments that produced a certain texture and groove might eventually be nominated as a 'verse' section, and another group - often larger sounding - would be nominated as the 'chorus'. Often in these songs there was no real key change. The bass line tended to remain constant, but one could still imply key modulations, illusory chord changes, which were very useful for building excitement while maintaining the trance-like feeling of constant root notes. Up to this point, there was still no top-line melody, nothing that the singer (me) would put words to. That came later (Byrne 2012: 157-58).

David Byrne's discussion of the compositional process for Remain In Light raises a number of questions about how far the compositional practices of the interviewees in this study are mirrored across other forms of popular music. One advantage that Byrne notes is the lack of attachment to any version of the material rehearsed by the band, because the compositional 
process had begun in the studio. It is probably no coincidence that Talking Head's producer for Remain in Light was Brian Eno, who discusses an "additive approach to recording" in his essay "The Studio as Compositional Tool":

You can begin to think in terms of putting something on, putting something else on, trying this on top of it, and so on, then taking some of the original things, or taking a mixture of things off, and seeing what you're left with-actually constructing a piece in the studio .... It puts the composer in the identical position of the painter-he's working directly with a material, working directly onto a substance, and he always retains the options to chop and change, to paint a bit out, add a piece, etc. (Eno 2004: 129).

Remain in Light was released in 1981, before digital sampling technology was widely available, and the compositional process developed by Byrne and Eno for the record anticipates the techniques used by sampling composers, once access to digital samplers became more commonplace. Given that any laptop loaded with DAW software can be thought of as a giant sampler (compared, say, to the sampling time offered by the $32 \mathrm{MB}$ of RAM in a fully expanded Akai $S 1000$ sampler in 1988), we can be confident that a "ground up" approach to songwriting, where the initial building blocks are groove and rhythm, rather than chords and melody, has become an increasingly common compositional practice, especially given the qualitative data gathered from interviews with songwriters working in popular music forms that are not traditionally sample-based (McIntyre 2001: 108-9). Perhaps the chief distinction between sampling composers and other popular music composers in this regard is that the foundations in their ground-up approach may often arrive ready-made.

\section{CONCLUSIONS}

Increasingly, the approach of the interviewees in this study may not differ especially from songwriters working in rock, country or pop, except perhaps that the groove is often the end in itself, and that they are working more purely with the relationships between timbre and groove than in other genres of music, while the way in which small sections of playing are often repeated magnifies their compositional importance in comparison to the sampled source material. In terms of compositional skill, listening is prioritised over both instrumental skill and an understanding of music theory, while the relative reluctance of our interviewees to incorporate the latest innovations in sample manipulation into their own compositions suggests that although affordable digital sampling technology certainly enabled non-traditional musicians to become composers, technological advances in this area are not necessarily altering compositional practices.

\section{NOTES}

1 Martin Reeves, interview with co-author (via telephone), 21 October 2011.

2 Paul Hammond, interview with co-author (online via Skype), 13 September 2012. 
3 Dean Honer, interview with co-author (Sheffield, UK), 15 September 2011.

4 Andy Carthy, interview with co-author (via telephone), 24 November 2011.

5 Richard Barratt, interview with co-author (via telephone), 3 November 2011.

6 Dean Honer, interview with co-author (Sheffield, UK), 15 September 2011.

7 Paul Hammond, interview with co-author (online via Skype), 13 September 2012.

8 Aston Harvey, interview with co-author (via telephone), 29 September 2011.

9 Richard Barratt, interview with co-author (via telephone), 3 November 2011.

10 Bob Bhamra, interview with co-author (via email), 11 September 2012.

11 Andy Carthy, interview with co-author (via telephone), 24 November 2011.

12 Andy Carthy, interview with co-author (via telephone), 24 November 2011.

13 Paul Hammond, interview with co-author (online via Skype), 13 September 2012.

14 Martin Reeves, interview with co-author (via telephone), 21 October 2011.

15 Richard Barratt, interview with co-author (via telephone), 3 November 2011.

16 Andy Carthy, interview with co-author (via telephone), 24 November 2011.

17 Martin Reeves, interview with co-author (via telephone), 21 October 2011.

18 Andy Carthy, interview with co-author (via telephone), 24 November 2011.

19 Dean Honer, interview with co-author (Sheffield, UK), 15 September 2011.

20 Dean Honer, interview with co-author (Sheffield, UK), 15 September 2011.

21 Paul Hammond, interview with co-author (online via Skype), 13 September 2012.

22 Andy Carthy, interview with co-author (via telephone), 24 November 2011.

23 Paul Hammond, interview with co-author (online via Skype), 13 September 2012.

\section{REFERENCES}

Aristotle. 1960. Metaphysics. Ann Arbor: Michigan University Press.

Barthes, Roland. 1977. “The Death of the Author”. In Image, Music, Text, 142-53. New York: Noonday Press.

Barthes, Roland. 1990. "The Grain of the Voice". In On Record: Rock, Pop and the Written Word, ed. Simon Frith and Andrew Goodwin, 293-300. London: Routledge.

Bennett, Joe. 2011. "Collaborative Songwriting-The Ontology of Negotiated Creativity in Popular Music Studio Practice”. Journal on the Art of Record Production 5. <http://arpjournal. com $/ 875 /$ collaborative-songwriting---the-ontology-of-negotiated-creativity-in-popularmusic-studio-practice/> (accessed 28 February 2014).

Bennett, Sam. 2010. "Examining The Emergence of Anti Production amongst the Popular Music Elite". PhD Thesis, Department of Music and Sound Recording, University of Surrey.

Bourdieu, Pierre. 1993. The Field of Cultural Production. New York: Columbia University Press. Burgess, Richard J. 1997. The Art of Record Production. London: Omnibus Press.

Byrne, David. 2012. How Music Works. Edinburgh: Canongate.

Chang, Vanessa. 2009. "Records that Play: The Present Past in Sampling Practice”. Popular Music 28(2): $143-59$. 
Csikszentmihalyi, Mihaly. 1988. "Society, Culture and Person: A Systems View of Creativity". In The Nature of Creativity: Contemporary Psychological Perspectives, ed. Robert J. Sternberg, 325-9. New York: Cambridge University Press.

Eno, Brian. 2004. “The Studio as Compositional Tool”. In Audio Culture: Readings in Modern Music, ed. Christopher Cox and Daniel Warner, 127-30. London: Continuum.

Fitzgerald, Jon. 1996. "Popular Songwriting 1963-1966: Stylistic Comparisons and Trends within the U.S. Top Forty”. PhD Thesis, Southern Cross University, Lismore, Australia.

Frith, Simon. 1996. Performing Rites: On the Value of Popular Music. Oxford: Oxford University Press.

Harkins, Paul. 2010. "Appropriation, Additive Approaches and Accidents: The Sampler as Compositional Tool and Recording Dislocation”. IASPM Journal 1(2): 1-19. < http://dx.doi. org/10.5429/2079-3871(2010)v1i2.3en > (accessed 28 February 2014).

Jensen, Klaus Bruhn and Nicholas W. Jankowski. 1991. A Handbook of Qualitative Methodologies for Mass Communication Research. London: Routledge.

Laing, David. 1990. "Listen to Me". In On Record: Rock, Pop and the Written Word, ed. Simon Frith and Andrew Goodwin, 326-40. London: Routledge.

Lull, James. 1990. Inside Family Viewing: Ethnographic Research on Television Audiences. London: Routledge.

McIntyre, Phillip. 2001. “The Domain of Songwriters-Towards Defining the Term Song”. Perfect Beat: The Pacific Journal of Research into Contemporary Music and Popular Culture 5(3): 100-11.

McIntyre, Phillip. 2009a. "The Systems Model of Creativity: Analyzing the Distribution of Power in the Studio". Journal of the Art of Record Production 3, < http://arpjournal.com/686/thesystems-model-of-creativity-analyzing-the-distribution-of-power-in-the-studio/> $>$ (accessed 23 February 2014).

McIntyre, Phillip. 2009b. "Rethinking Communication, Creativity and Cultural Production: Outlining Issues for Media Practice”. In Terry Flew (ed) Communication, Creativity and Global Citizenship: Refereed Proceedings of the Australian and New Zealand Communications Association Annual Conference <http://www.anzca.net/conferences/past-conferences/44adam.html $>$ (accessed 28 February 2014).

McIntyre, Phillip 2012. "How are Messages Created? Changes in Thinking about Communication Theory Leading to a New Synthesis”. In Chika Anyanwu, Kerry Green, \& Jolyon Sykes eds. Refereed Proceedings of the Australian and New Zealand Communication Association conference: Communicating Change and Changing Communication in the 21st Century, < http://www.anzca.net/past-conferences/past-conf-index.html > (accessed 23 February 2014).

McIntyre, Phillip and Justin Morey. 2011. "Working out the Split: Creative Collaboration and Assignation of Copyright across Differing Musical Worlds". Journal on the Art of Record Production 5, <http://arpjournal.com/849/working-out-the-split-creative-collaboration-andassignation-of-copyright-across-differing-musical-worlds/> (accessed 28 February 2014).

McIntyre, Phillip and Justin Morey. 2012. "Using the Tools and Techniques of Sampling in the Creative Practice of Record Producers in Britain". Journal on the Art of Record Production 7 , $<$ http://arpjournal.com/2165/examining-the-impact-of-multiple-technological-legal-socialand-cultural-factors-on-the-creative-practice-of-sampling-record-producers-in-britain/> (accessed 28 February 2014). 
Middleton, Richard. 1993. "Popular Music Analysis and Musicology: Bridging the Gap". Popular Music 12(2): 177-90.

Morey, Justin. 2012a. "The Bridgeport Dimension: Copyright Enforcement and its Implications for Sampling Practice”. In IASPM-Norden Music, Business \& Law Anthology, ed. Lee Marshall and Antti-Ville Kärjä, Helsinki: IASPM Norden \& Turku: International Institute for Popular Culture.

Morey, Justin. 2012b. "Copyright Management and its Implications for the Sampling Practice of UK Dance Music Producers". IASPM Journal, The Digital Nation: Copyright, Technology and Politics, ed. Geoff Stahl and Shane Homan, 3(1): 48-62, <http://www.iaspmjournal.net/ index.php/IASPM_Journal/article/view/589> (accessed 28 February 2014).

Nattiez, Jean-Jacques. 1990. Music and Discourse: Toward a Semiology of Music. trans. Carolyn Abbate. Princeton: Princeton University Press.

Reynolds, Simon. 2012. Retromania: Pop Culture's Addiction to its Own Past. London: Faber.

Rodgers, Tara. 2003. "On the Process and Aesthetics of Sampling in Electronic Music Production". Organised Noise 8(3): 313-20

Schloss, Joseph. 2004. Making Beats: The Art of Sample-Based Hip Hop. Middletown, CT: Wesleyan University Press.

Théberge, Paul. 1997. Any Sound You Can Imagine: Making Music/Consuming Technology. Hanover, NH: Wesleyan University Press.

Warner, Timothy. 2003. Pop Music: Technology and Creativity. Aldershot: Ashgate.

Wicke, Peter. 1990. Rock Music: Culture, Aesthetics and Sociology. Cambridge: Cambridge University Press.

Wolff, Janet. 1981. The Social Production of Art. London: Macmillan.

Yin, Robert. 1989. Case Study Research: Design and Methods. Newbury Park, CA: Sage.

\section{DISCOGRAPHY}

Krafty Kuts. 2006. Freakshow. Against The Grain (LP): ATGD04. < http://www.discogs.com/Krafty-Kuts-Freakshow/master/164474 >.

Fox, Peter. 2008. Alles Neu. Downbeat (CD Single): LC 04652. $<$ http://www.discogs.com/Peter-Fox-Alles-Neu/release/1741703 >.

New York Philharmonic Orchestra. 1965. Shostakovich, Symphony No. 7, Op. 60 "Leningrad". CBS (LP): S 72349/50. <http://www.discogs.com/Dmitri-Shostakovich-New-York-Philharmonic-Orchestra-The-LeonardBernstein-Shostakovich/release/4037070>.

Plan B. 2012. Ill Manors. 679 Recordings (CD Single): 679L179CD. <http://www.discogs.com/Plan-B-Ill-Manors/release/3493174 >.

Talking Heads. 1980. Remain in Light. Sire (LP): SRK 6095. < http://www.discogs.com/Talkingheads-Remain-In-Light/release/116491>. 


\section{SHORT BIOGRAPHIES OF INTERVIEWEES}

There follows some information about the sampling composers interviewed in this study:

a) Richard Barratt. Richard, better known as Parrot, is a DJ and producer who formed Sweet Exorcist (Warp Records) with Richard Kirk (Cabaret Voltaire), was a member of Add N to (X) and part of the dance act All Seeing I who had top 20 hits in the UK with the songs "Beat Goes On" (FFRR 1998) and "Walk Like A Panther" (London Records 1999).

b) Bob Bhamra is a DJ, producer and proprietor of UK underground dance label West Norwood Cassette Library (WNCL), with seventeen releases since 2010 at the time of writing.

c) Andy Carthy. Better known as Mr Scruff, Andy is a DJ and producer who has released over thirty singles since 1995 and five albums for the Ninja Tune label, including a UK top 30 album in Trouser Jazz (Ninja Tune 2002). He is also very well known in the UK for playing five to six hour DJ sets, incorporating a wide range of dance music genres, at his touring club night Keep It Unreal.

d) Paul Hammond. Paul is best know for his work with the duo Ultramarine, whose albums include Every Man And Woman Is A Star (Rough Trade 1992), United Kingdoms and Bel Air (Blanco Y Negro 1993 and 1995 respectively).

e) Aston Harvey has worked with artists including Rebel MC, Definition of Sound and DJ Rap. As part of Blapps Posse, he was responsible for the hit "Don't Hold Back" (Tribal Bass 1991), was a member of remix specialists The Sol Brothers, and is best known as one half of The Freestylers, along with Matt Cantor, who have produced albums and singles that have reached the top 40 both in the UK and Australia.

f) Dean Honer, like Richard Barratt, was a member of Add N to (X) and All Seeing I, and as part of I Monster he created a UK top 20 hit with “Daydream In Blue” (Dharma Records 2003), which samples the song "Daydream" by The Günter Kallman Choir (Polydor 1970). This led to Honer's involvement in the production of "Daydreamin" (Atlantic 2006) by US hip hop star Lupe Fiasco, which sampled I Monster's record. Honer also co-produced the Human League album Credo (Wall Of Sound 2011) and, with Barratt, has engaged in production work for Britney Spears.

g) Martin Reeves. Better known as Krafty Kuts, Martin is a well-known UK breakbeat producer and DJ with an extensive catalogue of over thirty of his own single releases, three studio albums, twelve mix albums and more than thirty remixes of other artists including Jurassic 5, Arthur Baker, Eric B. \& Rakim, Afrika Bambaataa and Fatboy Slim. 